\title{
Acyl-group specificity of AHL synthases involved in quorum- sensing in Roseobacter group bacteria
}

\author{
Lisa Ziesche ${ }^{1}$, Jan Rinkel ${ }^{2}$, Jeroen S. Dickschat ${ }^{2}$ and Stefan Schulz ${ }^{* 1}$
}

\author{
Full Research Paper \\ Address: \\ ${ }^{1}$ Institute of Organic Chemistry, Technische Universität \\ Braunschweig, Hagenring 30, 38106 Braunschweig, Germany and \\ ${ }^{2}$ Kekulé-Institute of Organic Chemistry and Biochemistry, University of \\ Bonn, Gerhard-Domagk-Str. 1, 53121 Bonn, Germany \\ Email: \\ Stefan Schulz* - stefan.schulz@tu-bs.de \\ * Corresponding author \\ Keywords: \\ Dinoroseobacter shibae; fatty acid composition; $\mathrm{N}$-acylhomoserine
}

lactones; quorum sensing; Phaeobacter inhibens
Beilstein J. Org. Chem. 2018, 14, 1309-1316.

doi:10.3762/bjoc. 14.112

Received: 12 February 2018

Accepted: 14 May 2018

Published: 05 June 2018

Associate Editor: K. N. Allen

(C) 2018 Ziesche et al.; licensee Beilstein-Institut. License and terms: see end of document.

\begin{abstract}
$\mathrm{N}$-Acylhomoserine lactones (AHLs) are important bacterial messengers, mediating different bacterial traits by quorum sensing in a cell-density dependent manner. AHLs are also produced by many bacteria of the marine Roseobacter group, which constitutes a large group within the marine microbiome. Often, specific mixtures of AHLs differing in chain length and oxidation status are produced by bacteria, but how the biosynthetic enzymes, LuxI homologs, are selecting the correct acyl precursors is largely unknown. We have analyzed the AHL production in Dinoroseobacter shibae and three Phaeobacter inhibens strains, revealing strain-specific mixtures. Although large differences were present between the species, the fatty acid profiles, the pool for the acyl precursors for AHL biosynthesis, were very similar. To test the acyl-chain selectivity, the three enzymes LuxI $I_{1}$ and LuxI $_{2}$ from $D$. shibae DFL-12 as well as $\mathrm{PgaI}_{2}$ from $P$. inhibens DSM 17395 were heterologously expressed in E. coli and the enzymes isolated for in vitro incubation experiments. The enzymes readily accepted shortened acyl coenzyme A analogs, $N$-pantothenoylcysteamine thioesters of fatty acids (PCEs). Fifteen PCEs were synthesized, varying in chain length from $\mathrm{C}_{4}$ to $\mathrm{C}_{20}$, the degree of unsaturation and also including unusual acid esters, e.g., 2E,11Z-C18:2-PCE. The latter served as a precursor of the major AHL of D. shibae DFL-12 LuxI $_{1}, 2 E, 11 Z-C 18: 2$-homoserine lactone (HSL). Incubation experiments revealed that $\mathrm{PgaI}_{2}$ accepts all substrates except $\mathrm{C}_{4}$ and $\mathrm{C}_{20}$-PCE. Competition experiments demonstrated a preference of this enzyme for $\mathrm{C}_{10}$ and $\mathrm{C}_{12}$ PCEs. In contrast, the LuxI enzymes of $D$. shibae are more selective. While 2E,11Z-C18:2-PCE is preferentially accepted by $\mathrm{LuxI}_{1}$, all other PCEs were not, except for the shorter, saturated $\mathrm{C}_{10}-\mathrm{C}_{14}$-PCEs. The AHL synthase LuxI 2 accepted only $\mathrm{C}_{14}$ PCE and 3-hydroxydecanoyl-PCE. In summary, chain-length selectivity in AHLs can vary between different AHL enzymes. Both, a broad substrate acceptance and tuned specificity occur in the investigated enzymes.
\end{abstract}




\section{Introduction}

The Roseobacter group, a subgroup of the Rhodobacteraceae family, constitutes an important class of Gram-negative marine bacteria, occurring in many different habitats $[1,2]$, in fresh water as well as on surfaces [3]. They can produce a variety of secondary metabolites, including antibiotics [4,5], volatile compounds [6,7], oligohydroxybutyrates [8] and a range of $N$-acylhomoserine lactones (AHLs) [8-10]. AHLs are quorum-sensing signaling compounds that are used for cell-cell communication to regulate several physiological traits regulated by cell density, the 'quorum' [11-16], in roseobacters, e.g., in the production of the antibiotic tropodithietic acid in Phaeobacter inhibens [15] and cell differentiation in Dinoroseobacter shibae [14]. Roseobacter group AHLs are characterized by saturated, unsaturated and sometimes oxygenated acyl chains ranging in length between $\mathrm{C}_{8}$ and $\mathrm{C}_{18}$ [8] with the exception of the aromatic $p$-coumaroylhomoserine lactone produced by Rugeria pomeroyi DSS-3 [17].

In a recent analysis we showed the AHL presence in 19 out of 24 Roseobacter group bacterial strains isolated from macroalgal surfaces [8]. The most widespread AHL was 7-tetradecenoylhomoserine lactone (7-C14:1-HSL), present in seven strains. No clear correlation between phylogeny and AHL occurrence was observed. In some strains only one AHL was detected, while others such as $P$. gallaeciensis BS107 produced eight different AHLs [8].

The biosynthesis of AHLs is mediated by the enzyme LuxI or its homologs, and often accompanied by a regulator protein, LuxR $[18,19]$. An ACP-bound fatty acid acyl group $\mathbf{1}$ is transferred onto the amino group of $S$-adenosylmethionine (SAM, 2) that is followed by substitution of the good leaving group 5 '-deoxy-5'-thiomethyladenosine (5) of the thioester group, leading to homoserine lactone 4 formation (Scheme 1). Recently a LuxI-homolog, BjaI [20] preferring acyl-coenzyme A (CoA) substrates instead of the common ACP precursors, was characterized [21].

The LuxI-type enzymes are the most widespread and best understood AHL synthases. Four structures of LuxI-type en- zymes have been published, covering both ACP and CoA-dependent structures with various chain lengths and different oxidation states of the acyl chain at C-3 [21-24]. A great diversity among AHL synthases is observed. The preference for unsubstituted, 3-oxo or 3-hydroxyacyl precursors is mediated by binding interactions inside the active site of AHL synthases $[18,21]$. Investigations on the chain-length selectivity of the AHL synthases are limited. BjaI can accept substrates ranging from isovaleryl-CoA, the native substrate, up to isononanoylCoA [21].

Three different LuxI homologs, $\operatorname{LuxI}_{1}, \mathrm{LuxI}_{2}$, and $\mathrm{LuxI}_{3}$, occur in Dinoroseobacter shibae DFL-12 [14]. Recently, we were surprised to find that the structures of AHLs synthesized by a LuxI homolog from $D$. shibae DFL-12 depended on the host in which the enzyme was expressed [10]. Expression of $\mathrm{LuxI}_{1}$ in E. coli led to a predominant formation of a 2:1:0.3 mixture of 9-C18:1-homoserine lactone (HSL), C16:0-HSL and C14:0HSL, while the overexpression in its parent strain furnished the native product, $2 E, 11 Z-\mathrm{C} 18: 2-\mathrm{HSL}$, accompanied by $4 \%$ each of 9-C18:1-HSL and 2,9-C16:2-HSL. While the native substrates of $\mathrm{LuxI}_{2}$ and $\mathrm{LuxI}_{3}$ were not detected because of their low concentration, their overexpression in $E$. coli led to the production of a 6:1 mixture of 7Z-C14:1-HSL and C14:0-HSL for $\mathrm{LuxI}_{2}$ and no AHL formation for $\mathrm{LuxI}_{3}$ [10]. The differences between the AHLs in terms of chain length and degree of unsaturation prompted us to investigate the acyl-chain selectivity of LuxI-type enzymes in roseobacters. Does the enzyme have an inherent selectivity for a specific acyl-chain precursor or does it react unselectively with every acyl-precursor available? In the latter case the presence of the acyl precursors would determine the structure of the final AHL. To answer this question, the fatty acid composition of the native roseobacters was determined and compared to the AHLs produced. In addition, LuxI-type enzymes were heterologously expressed in E. coli and the purified recombinant enzymes were tested with different precursors to probe their selectivity. Both model organisms of the Roseobacter group, $P$. inhibens (formerly P. gallaeciensis [25]) DSM17395 and Dinoroseobacter shibae DFL-12, were investigated, together with closely related $P$. inhibens strains T5 and

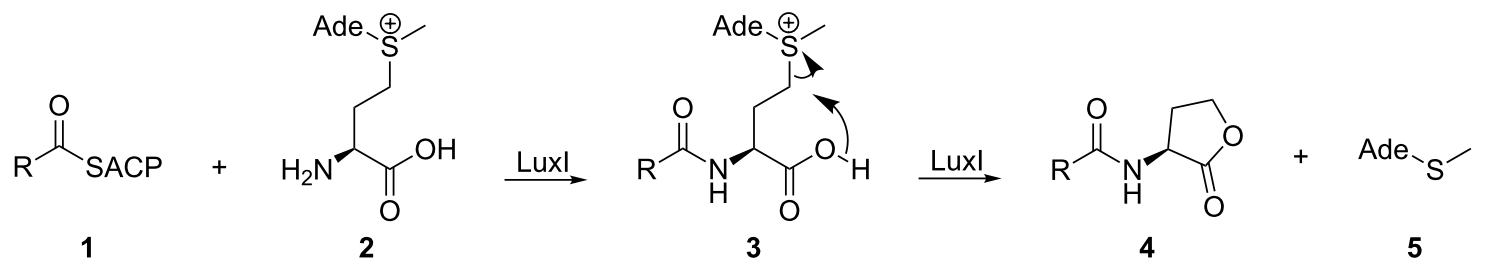

Scheme 1: Biosynthesis of AHLs by ACP-dependent Luxl type enzymes. 
2.10 [26], to investigate strain variability. Previously, the LuxI homolog $\mathrm{PgaI}_{1}$ from $P$. inhibens DSM 17395 has been characterized, producing $R-3-\mathrm{OH}-\mathrm{C} 10: 0-\mathrm{HSL}[15,27]$. This strain produced additionally long chain AHLs such as C18:1-HSL [9] and contains a second AHL synthase, $\mathrm{PgaI}_{2}$ [28], probably involved in the biosynthesis of the long chain AHLs. Here we report on the characterization of $\mathrm{PgaI}_{2}$ from P. inhibens and of $\mathrm{LuxI}_{1}$ and $\mathrm{LuxI}_{2}$ from $D$. shibae by in vitro incubation experiments.

\section{Results and Discussion}

The AHL production of four Roseobacter group strains was analyzed by a GC/MS-based method using XAD-16 as adsorbent in marine broth, developed by us [8]. The bacteria were isolated from different habitats: $D$. shibae DFL-12 was isolated from the dinoflagellate Prorocentrum lima [29], P. inhibens T5 was collected from a water sample of the German Wadden Sea [30], P. inhibens DSM17395 was isolated from seawater of larval cultures of the scallop Pecten maximus in Spain [25] and $P$. inhibens 2.10 stemmed from the surface of the green macroalga Ulva australis in Australia [31].

The results showed that $P$. inhibens 2.10 and $P$. inhibens DSM17395 produce the same four AHLs, 3-OH-C10:0-HSL as major components and known from previous analyses of P. inhibens [9,32], C16:0-HSL, C16:1-HSL, and C18:1-HSL (Table 1). P. inhibens T5 additionally produced 3-oxo-C10:0HSL and C12:2-HSL with unknown location of the double bonds. D. shibae DFL-12 released C14:1-HSL, 3-oxo-C14HSL, C18:1-HSL, and C18:2-HSL, similar to previous results $[10,16]$.

In addition, the fatty acid profile of the four strains was determined. Therefore, bacterial colonies from agar plates were added to $20 \mu \mathrm{L}$ of methanolic trimethylsulfonium hydroxide (TMSH) solution. This procedure lyses the bacteria and concomitantly transfers any bound or free fatty acid into its methyl ester (FAME) [33]. The extracts were analyzed by GC/MS (Figure 1). Short and long FAMEs were detected, ranging from methyl octanoate to methyl icosanoate (Table 2). The three
Phaeobacter strains produced identical fatty acids. We identified FAMEs with a C8:0, C12:0, C12:1, C16:0, C16:1, C17:0, C18:2, C18:0, C18:1, and C19:1 chain, the three last ones being the most abundant. D. shibae DFL-12 showed a similar fatty acid production, but no FAMEs with $\mathrm{C}_{8}$ or $\mathrm{C}_{12}$ chains were detected. Instead, 3-OH-C10:0-HSL, C14:0, and C20:0 FAMEs occurred in addition.

The location of the double bond of the major acids was determined by dimethyl disulfide (DMDS) derivatization [32,34]. The fragment ions at $m / z 145$ and 161 of the DMDS-derivative and the secondary fragments obtained by loss of the methyl ester group $(m / z 129)$ located the position of the double bond in C12:1-FAME at C-5. Similarly, 9-C16:1 ( $\mathrm{m} / \mathrm{z} 145,185,217)$ and 11-C18:1-FAMEs $(m / z 145,213,245)$ were assigned. The three Phaeobacter strains showed also a small peak with identical mass spectrum compared to 11-C18:1-FAME eluting slightly earlier than the major compound, indicating minor amounts of 11E-C18:1-FAME next to the major 11Z-C18:1FAME. DMDS adducts derived from $E$-configured double bonds elute slightly earlier than their $Z$-configured counterparts on apolar GC phases [34]. All four strains additionally contained 13-C18:1-FAME $(m / z$ 61, 117, 241 and 273) in small amounts. The mass spectrum of C19:1-FAME differed from that of methyl nonadecenoate, but was identical to that of methyl 11-methyl-12-octadecenoate $[29,35,36]$, as was that of its DMDS derivative $(m / z 131,241,273$, see Figures S1 and S2 in the Supporting Information File 1). Similarly, 13-C20:1 was identified in D. shibae DFL-12. Small amounts of a DMDS adduct of C18:2 were detected that added only one equivalent of DMDS. This reactivity is observed when a double bond is conjugated with a carbonyl group [37,38]. The ion at $m / z 145$ located one double bond at C-11, while the ions at $\mathrm{m} / \mathrm{z} 211$ and 243 revealed another unsaturation in the alkyl chain towards the carboxy terminus. These data indicate this FAME to be 2,11C18:1, the parent acid of the major D. shibae AHL, 2E,11ZC18:2-HSL [10]. The analysis performed with bacteria grown in liquid medium led to comparable results, indicating that the fatty acid composition does not depend on the culture method.

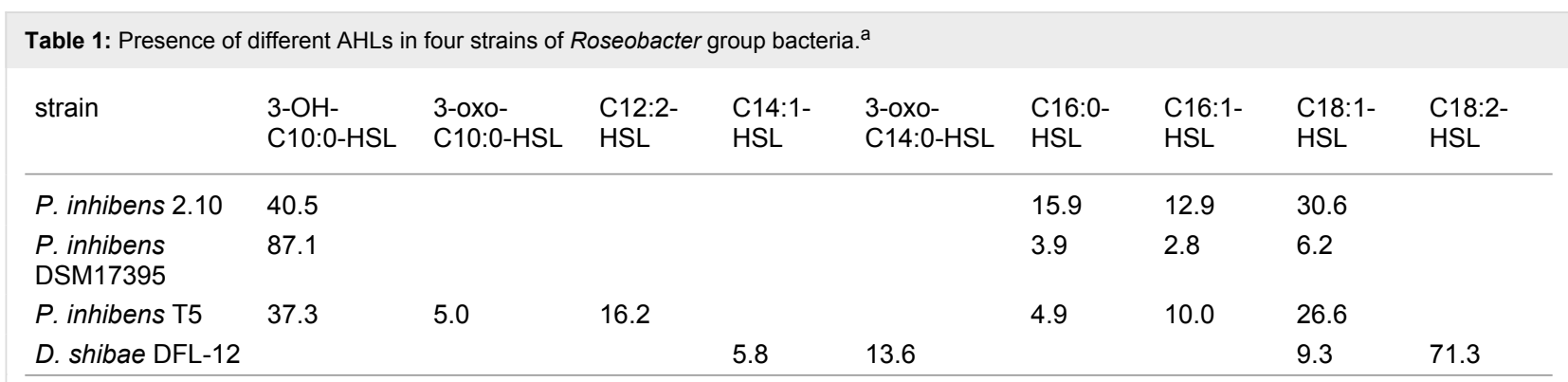

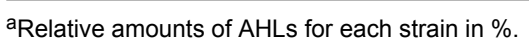



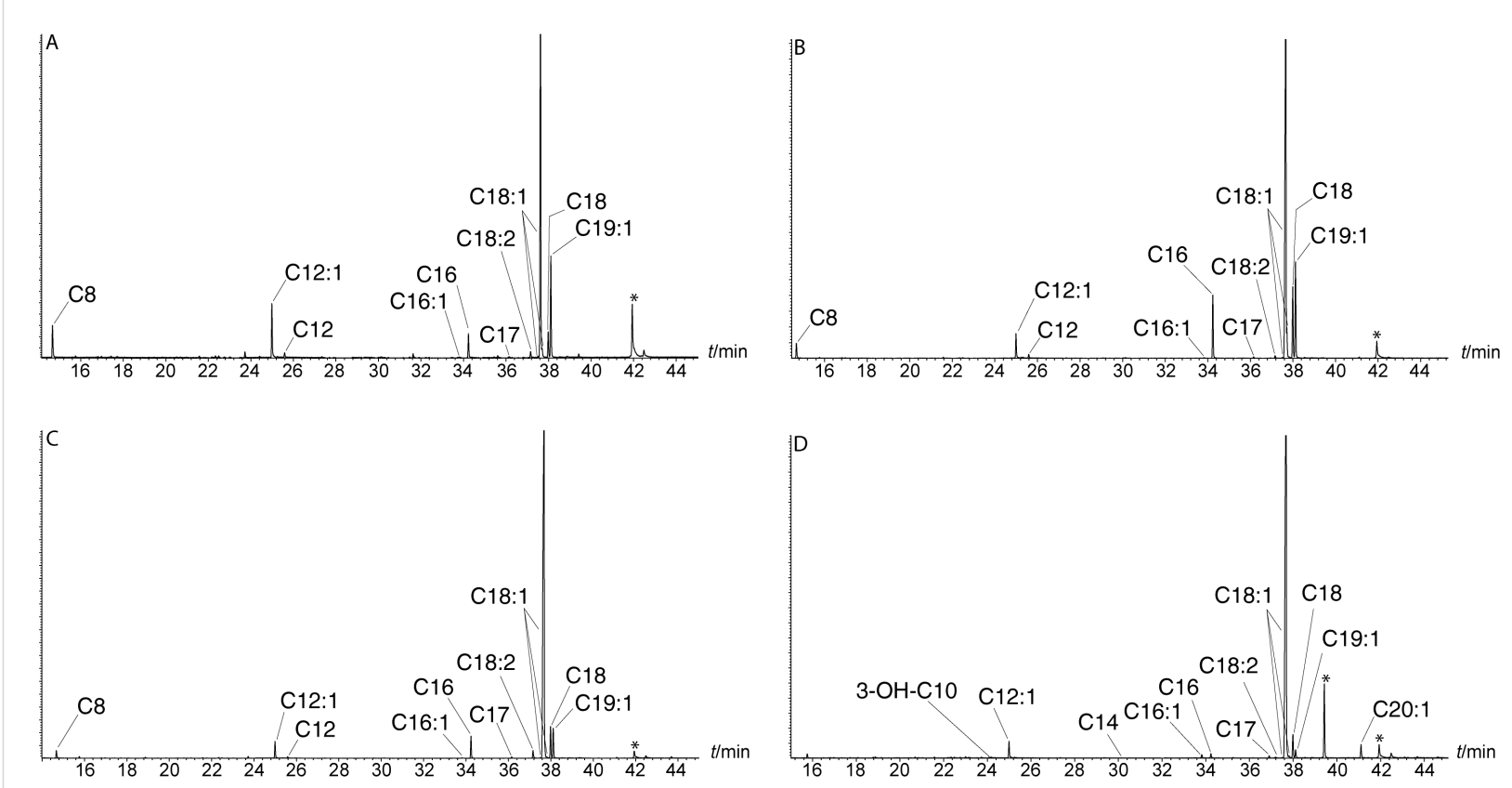

Figure 1: Total ion chromatograms of the FAME extracts of A) $P$. inhibens $2.10, \mathrm{~B}) P$. inhibens DSM17395, C) $P$. inhibens T5 and D) $D$. shibae DFL12. *other compounds.

Table 2: Presence of bound or free fatty acids in four different Roseobacter group strains detected as methyl esters. ${ }^{a}$

\begin{tabular}{|c|c|c|c|c|c|c|c|c|}
\hline & \multicolumn{3}{|c|}{$P$. inhibens } & D. shibae & \multicolumn{3}{|c|}{$P$. inhibens } & D. shibae \\
\hline & \multicolumn{4}{|c|}{ agar plate } & \multicolumn{4}{|c|}{ liquid culture } \\
\hline & 2.10 & DSM17395 & T5 & DFL-12 & 2.10 & DSM17395 & T5 & DFL 12 \\
\hline C8:0 & 5.0 & 1.8 & 1.0 & & 0.1 & 0.9 & 0.2 & \\
\hline 3-OH-C10:0-HSL & & & & 0.1 & & & & 0.5 \\
\hline C12:0 & 0.6 & 0.4 & 0.2 & & 0.1 & 0.2 & 0.1 & \\
\hline $5 Z-C 12: 1$ & 8.2 & 2.9 & 2.2 & 2.3 & 0.5 & 2.2 & 0.9 & 0.8 \\
\hline C14:0 & & & & $<0.1$ & & & & 0.1 \\
\hline C16:0 & 3.8 & 7.5 & 3.0 & 0.6 & 4.3 & 2.6 & 2.2 & 0.3 \\
\hline 9Z-C16:1 & 0.1 & $<0.1$ & $<0.1$ & 0.5 & 0.1 & 0.1 & $<0.1$ & 0.2 \\
\hline C17:0 & 0.4 & 0.2 & 0.2 & $<0.1$ & 0.1 & 0.1 & 0.1 & $<0.1$ \\
\hline C18:0 & 3.9 & 8.6 & 4.6 & 2.6 & 2.1 & 1.8 & 1.8 & 3.4 \\
\hline 11Z-C18:1 & 60.4 & 66.7 & 83.1 & 91.9 & 61.0 & 67.8 & 67.3 & 92.4 \\
\hline 11E-C18:1 & 0.3 & 0.1 & 0.1 & $<0.1$ & 0.1 & 0.1 & 0.1 & 0.1 \\
\hline 13Z-C18:1 & 0.4 & $<0.1$ & $<0.1$ & 0.1 & 1.2 & 1.0 & 1.0 & 0.3 \\
\hline $2 E, 11 Z-C 18: 2$ & 1.2 & 0.3 & 1.2 & $<0.1$ & 3.2 & 1.8 & 2.9 & $<0.1$ \\
\hline $11 \mathrm{Me}-12 E-\mathrm{C} 19: 1$ & 15.7 & 11.4 & 4.3 & 0.6 & 27.2 & 21.5 & 23.4 & 1.0 \\
\hline 13Z-C20:1 & & & & 1.2 & & & & 0.9 \\
\hline
\end{tabular}

aRelative peak areas of FAMEs for each strain in \%.

By comparing the fatty acid profiles and AHL production no direct correlation between fatty acids and AHLs can be observed. The major acid C18:1 is only reflected by a minor component in the AHL profile of the four strains. Small amounts of
2,11-C18:2 occur in all strains, only the D. shibae strain uses this acid as precursor for its major 2,11-C18:2-HSL. In contrast, the precursor acid 3-OH-C10:0-HSL is produced by D. shibae, but not present in the profiles of $P$. inhibens, which produces 
large amounts of 3-OH-C10:0-HSL. Furthermore, the prominent acid 11Me-12-C18:1 is not used for AHL formation. Acids used for production of minor AHLs such as C14:1 or C12:2 were not detected.

These results show that the fatty acid pool and AHL formation are indeed uncoupled. Although the fatty acid composition of the investigated strains is very similar, the AHL production differs largely. The complete absence or presence of only minor amounts of precursor acids of AHLs such as 2,11-C18:2 or 3-OH-C10:0-HSL might indicate that they are available only for AHL biosynthesis, but are not used for other physiological purposes. Such acids may be immediately transformed after their biosynthesis into an AHL, or are stored in a form not cleavable by the TMSH method used. These precursor acids may also originate from fatty acid degradation, a pathway that proceeds via free coenzyme A intermediates and not via acyl carrier protein-bound substrates like in the fatty acid biosynthesis.

These results led to the question whether the acyl-chain selectivity is an inherent property of the AHL synthase itself or whether this is determined by other factors, e.g., precursor availability. Therefore, LuxI-type synthases from D. shibae
(LuxI $1, \operatorname{LuxI}_{2}$ ) and from $P$. inhibens DSM17395 (PgaI 2$)$ were cloned and expressed in E. coli to allow in vitro experiments with suitable acyl precursors to probe AHL formation. After protein purification of the AHL synthases and incubation with the precursors $S$-adenosyl methionine (SAM) and different acyl derivatives (free fatty acids, SNAC esters, PCEs) the AHL production was determined using GC/MS [9,10,32]. Coenzyme A or abbreviated ACP analogs, $N$-pantothenoylcysteamine thioesters of fatty acids (PCEs) were synthesized (Scheme 2) to serve as substrate substitutes for the native precursors.

Calcium pantothenate (6) was protected with acetone forming acid 7 that was transformed with cysteamine into the protected thiol 8 [39]. Steglich esterification [40] with different free acids led to nine saturated PCEs $10 a-\mathbf{i}$, four monounsaturated acids (11a-d), 3-OH-C10:0-HSL PCE (12), and 2E,11Z-C18:2-PCE (13) after deprotection with acetic acid [41]. Although compounds 10-13 can be further purified by HPLC, the crude products proved to be pure enough for the next experiments.

The incubation experiments were performed with the three recombinant AHL synthases, SAM, and the different precursors 10-13. The AHL-synthase $\mathrm{PgaI}_{2}$ of $P$. inhibens showed a higher activity compared to the two $D$. shibae synthases. It<smiles>CC1(C)OCC(C)(C)C(C(=O)NCCC(=O)O)O1</smiles><smiles>[R]C(=O)SCCNC(=O)CCNC(=O)[C@@H]1OC(C)(C)OCC1(C)C</smiles><smiles>CC(C)(C)CCC(=O)SCCNC(=O)CCNC(=O)C(O)C(C)(C)CO</smiles>

10a: $n=1$ 10d: $n=4$ 10g: $n=7$

10b: $n=2$ 10e: $n=5$ 10h: $n=8$

10c: $n=3$ 10f: $n=6$ 10i: $n=9$<smiles>[Y20]=S</smiles><smiles>CCCCCCCCCC(=O)SCCNC(=O)CCNC(=O)[C@H](O)C(C)(C)CO</smiles>

11a: $n=2, m=2$

11b: $n=3, m=3$

11c: $n=3, m=2$

11d: $n=4, m=2$ 
accepted all substrates, including unsaturated ones, with the exclusion of the very short C4:0 and very long C20:0-PCEs.

The AHL-synthase $\mathrm{LuxI}_{2}$ was able to produce C14:0-HSL and 3-OH-C10-HSL in low concentration from the respective precursors. It is likely responsible for the formation of C14:0-HSL and 3-oxo-C14:0-HSL in D. shibae DFL-12. The AHL synthase LuxI $_{1}$ used five precursors to synthesize C8:0, C10:0, C12:0 and C14:0-HSL in low amounts, while 2E,11Z-C18:2-HSL, its native product, is formed in high concentration.

To further evaluate the selectivity of the promiscuous enzyme $\mathrm{PgaI}_{2}$ from $P$. inhibens, competition experiments were performed. Targeting the optimal chain length of the fully saturated substrates first, a mixture with equal molar concentrations of the substrates $10 \mathbf{a}-\mathbf{h}$ was offered to the recombinant protein. GC/MS analysis of the resulting extract (Figure 2A) revealed a distribution of AHL products around the chain length of $\mathrm{C}_{10}$ and $\mathrm{C}_{12}$, which were shown to be the most prominent products. In a second experiment with substrates $10 \mathbf{a}-\mathbf{i}, \mathbf{1 1 a}-\mathbf{c}$, and 12 also unsaturated substrates and the hydroxylated precursor were tested (Figure 2B). It turned out that the same distribution of the saturated AHLs as for the first experiment was observed with none of the additional substrates showing a significantly higher conversion. These results point to a very flexible active site of the investigated AHL synthase $\mathrm{PgaI}_{2}$, which converts a variety of substrates. The highest conversion efficiency in the competition experiments was found for the saturated substrates 10c and 10d with lower abundance of any AHL products deviating from this chain length. It should be noted that the amount of added SAM was not sufficient to convert all substrates, so the product spectrum likely reflects different enzyme kinetics for the PCE substrates. In contrast, in the single-substrate incubation experiments (Table 3) an excess of SAM was used, and this may have led to the formation even of products that are disfavored in the competition experiments.
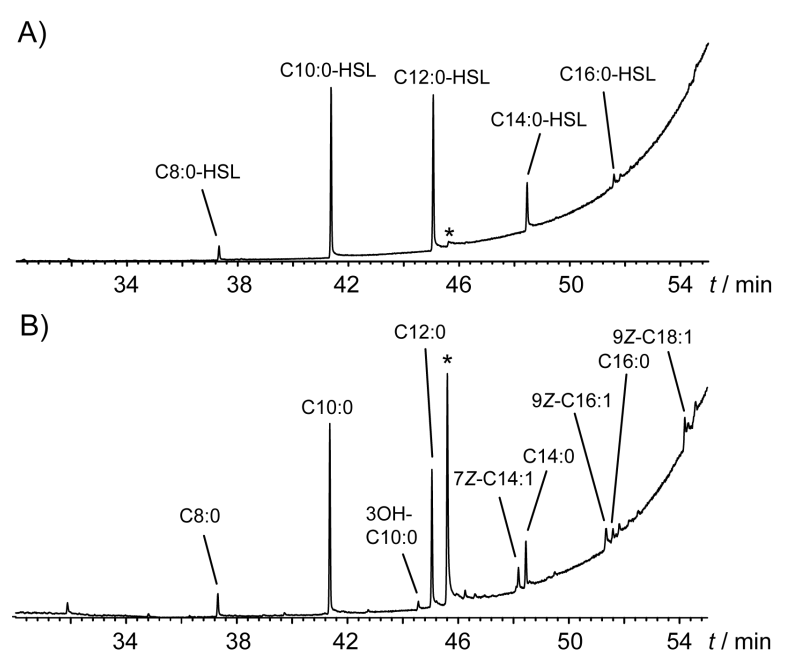

Figure 2: Total ion chromatograms of the extracts from competition experiments using recombinant $\mathrm{Pgal}_{2}$ from $P$. inhibens with $\mathrm{SAM}$ and a mixture of equally concentrated substrates $A$ ) $10 a-h$ (saturated chains $\mathrm{C}_{4}-\mathrm{C}_{18}$ ) and B) $10 \mathrm{a}-\mathbf{i}, \mathbf{1 1 a}-\mathbf{c}$ and 12. Prominent contaminants are indicated by asterisks.

\begin{tabular}{|c|c|c|c|c|}
\hline Precursor & $\mathrm{AHL}$ & $\begin{array}{l}\text { P. inhibens } \\
\text { Pgal }_{2}\end{array}$ & $\begin{array}{l}\text { D. shibae } \\
\text { Luxl }_{1}\end{array}$ & $\begin{array}{l}\text { D. shibae } \\
\text { LuxI }_{2}\end{array}$ \\
\hline $10 a$ & $\mathrm{C} 4: 0$ & - & - & - \\
\hline $10 \mathrm{~b}$ & $\mathrm{C} 6: 0$ & $x$ & - & - \\
\hline $10 c$ & $\mathrm{C} 8: 0$ & $x x$ & $x$ & - \\
\hline $10 d$ & C10:0 & $x x$ & $x$ & - \\
\hline $10 \mathrm{e}$ & C12:0 & $x x$ & $x$ & - \\
\hline $10 f$ & $\mathrm{C} 14: 0$ & $x x$ & $x$ & $x$ \\
\hline $10 \mathrm{~g}$ & C16:0 & $x$ & - & - \\
\hline $10 \mathrm{~h}$ & C18:0 & $x$ & - & - \\
\hline $10 i$ & C20:0 & - & - & - \\
\hline 12 & 3-OH-C10:0 & $x x$ & - & $x$ \\
\hline $11 a$ & $7 Z-C 14: 1$ & $x x$ & - & - \\
\hline $11 b$ & 9Z-C16:1 & $x x$ & - & - \\
\hline 11c & 9Z-C18:1 & $x x$ & - & - \\
\hline $11 d$ & 11Z-C18:1 & $x x$ & - & - \\
\hline 13 & $2 E, 11 Z-C 18: 2$ & $x x$ & $x x$ & - \\
\hline
\end{tabular}

${ }^{a} x$ : high production, $x$ : low production, -: no production. 


\section{Conclusion}

The results showed that the enzymes exhibit varying substrate plasticity. While the $P$. inhibens synthase $\mathrm{PgaI}_{2}$ accepted most precursors, the best performance was observed with the saturated substrates harboring $\mathrm{C}_{10}$ or $\mathrm{C}_{12}$ chain lengths. In $P$. inhibens this enzyme is most likely responsible for the biosynthesis of long-chain AHLs. In contrast, D. shibae synthase LuxI $_{1}$ showed a high selectivity for $2 E, 11 Z$-C18:2-HSL and did not even accept similar substrates such as $11 \mathrm{c}$ or 11d. Interestingly, considerably shorter saturated substrates, e.g., 10e, are accepted. The $D$. shibae synthase $\mathrm{LuxI}_{2}$ synthase was even more selective. It seems likely that other factors than AHL synthase substrate specificity influence the observed formation of only certain AHLs by these wild-type enzymes. These factors might include selectivity found in enzymes activating or transporting acids to AHL synthases, or interact with the LuxI enzyme, either directly or indirectly. The combination of the different selectivity levels may eventually lead to the specific mixtures observed in the different AHL producing bacterial strains.

\section{Supporting Information}

\section{Supporting Information File 1}

Experimental, mass spectra, SDS page and NMR spectra. [https://www.beilstein-journals.org/bjoc/content/ supplementary/1860-5397-14-112-S1.pdf]

\section{Acknowledgements}

We thank the Deutsche Forschungsgemeinschaft for supporting our work through the Transregional Collaborative Research Centre "Roseobacter" (SFB TRR 51/3) and the Fonds der Chemischen Industrie for a Ph.D. scholarship (to JR). Gene cloning by Seocho Kim is gratefully acknowledged.

\section{ORCID ${ }^{\circledR}$ iDs}

Jeroen S. Dickschat - http://orcid.org/0000-0002-0102-0631 Stefan Schulz - http://orcid.org/0000-0002-4810-324X

\section{References}

1. Giebel, H.-A.; Kalhoefer, D.; Lemke, A.; Thole, S.; Gahl-Janssen, R.; Simon, M.; Brinkhoff, T. ISME J. 2011, 5, 8-19. doi:10.1038/ismej.2010.87

2. Selje, N.; Simon, M.; Brinkhoff, T. Nature 2004, 427, 445-448. doi:10.1038/nature02272

3. Freese, H. M.; Methner, A.; Overmann, J. Front. Microbiol. 2017, 8, No. 1659. doi:10.3389/fmicb.2017.01659

4. Brock, N. L.; Nikolay, A.; Dickschat, J. S. Chem. Commun. 2014, 50, 5487-5489. doi:10.1039/c4cc01924e

5. Seyedsayamdost, M. R.; Case, R. J.; Kolter, R.; Clardy, J. Nat. Chem. 2011, 3, 331-335. doi:10.1038/nchem.1002
6. Thiel, V.; Brinkhoff, T.; Dickschat, J. S.; Wickel, S.; Grunenberg, J.; Wagner-Döbler, I.; Simon, M.; Schulz, S. Org. Biomol. Chem. 2010, 8, 234-246. doi:10.1039/B909133E

7. Brock, N. L.; Menke, M.; Klapschinski, T. A.; Dickschat, J. S. Org. Biomol. Chem. 2014, 12, 4318-4323. doi:10.1039/c4ob00719k

8. Ziesche, L.; Bruns, H.; Dogs, M.; Wolter, L.; Mann, F.; Wagner-Döbler, I.; Brinkhoff, T.; Schulz, S. ChemBioChem 2015, 16, 2094-2107. doi:10.1002/cbic.201500189

9. Wagner-Döbler, I.; Thiel, V.; Eberl, L.; Allgaier, M.; Bodor, A.; Meyer, S.; Ebner, S.; Hennig, A.; Pukall, R.; Schulz, S. ChemBioChem 2005, 6, 2195-2206. doi:10.1002/cbic.200500189

10. Neumann, A.; Patzelt, D.; Wagner-Döbler, I.; Schulz, S. ChemBioChem 2013, 14, 2355-2361. doi:10.1002/cbic.201300424

11. Buchan, A.; Mitchell, A.; Cude, W. N.; Campagna, S. Acyl-Homoserine Lactone-Based Quorum Sensing in Members of the Marine Bacterial Roseobacter Clade: Complex Cell-to-Cell Communication Controls Multiple Physiologies. In Stress and Environmental Regulation of Gene Expression and Adaptation in Bacteria; de Bruijn, F. J., Ed.; Wiley Blackwell, 2016; pp 225-233. doi:10.1002/9781119004813.ch19

12. Zan, J.; Liu, Y.; Fuqua, C.; Hill, R. T. Int. J. Mol. Sci. 2014, 15, 654-669. doi:10.3390/ijms15010654

13. Schulz, S.; Hötling, S. Nat. Prod. Rep. 2015, 32, 1042-1066. doi:10.1039/C5NP00006H

14. Patzelt, D.; Wang, H.; Buchholz, I.; Rohde, M.; Gröbe, L.; Pradella, S.; Neumann, A.; Schulz, S.; Heyber, S.; Münch, K.; Münch, R.; Jahn, D.; Wagner-Döbler, I.; Tomasch, J. ISME J. 2013, 7, 2274-2286. doi:10.1038/ismej.2013.107

15. Berger, M.; Neumann, A.; Schulz, S.; Simon, M.; Brinkhoff, T. J. Bacteriol. 2011, 193, 6576-6585. doi:10.1128/JB.05818-11

16. Wang, H.; Ziesche, L.; Frank, O.; Michael, V.; Martin, M.; Petersen, J.; Schulz, S.; Wagner-Döbler, I.; Tomasch, J. BMC Genomics 2014, 15, No. 130. doi:10.1186/1471-2164-15-130

17. Schaefer, A. L.; Greenberg, E. P.; Oliver, C. M.; Oda, Y.; Huang, J. J.; Bittan-Banin, G.; Peres, C. M.; Schmidt, S.; Juhaszova, K.; Sufrin, J. R.; Harwood, C. S. Nature 2008, 454, 595-599. doi:10.1038/nature07088

18. Churchill, M. E. A.; Herman, J. P. Acyl-homoserine lactone biosynthesis: structure and mechanism. In Chemical communication among bacteria; Winans, S. C.; Bassler, B. L., Eds.; ASM Press: Washington, DC, 2008; pp 275-289. doi:10.1128/9781555815578.ch17

19. Dickschat, J. S. Nat. Prod. Rep. 2010, 27, 343-369. doi:10.1039/b804469b

20. Dong, S.-H.; Frane, N. D.; Christensen, Q. H.; Greenberg, E. P.; Nagarajan, R.; Nair, S. K. Proc. Natl. Acad. Sci. U. S. A. 2017, 114, 9092-9097. doi:10.1073/pnas.1705400114

21. Lindemann, A.; Pessi, G.; Schaefer, A. L.; Mattmann, M. E.; Christensen, Q. H.; Kessler, A.; Hennecke, H.; Blackwell, H. E.; Greenberg, E. P.; Harwood, C. S. Proc. Natl. Acad. Sci. U. S. A. 2011, 108, 16765-16770. doi:10.1073/pnas.1114125108

22. Chung, J.; Goo, E.; Yu, S.; Choi, O.; Lee, J.; Kim, J.; Kim, H.; Igarashi, J.; Suga, H.; Moon, J. S.; Hwang, I.; Rhee, S. Proc. Natl. Acad. Sci. U. S. A. 2011, 108, 12089-12094. doi:10.1073/pnas.1103165108

23. Gould, T. A.; Schweizer, H. P.; Churchill, M. E. A. Mol. Microbiol. 2004, 53, 1135-1146. doi:10.1111/j.1365-2958.2004.04211.x

24. Watson, W. T.; Minogue, T. D.; Val, D. V.; Beck von Bodman, S.; Churchill, M. E. A. Mol. Cell 2002, 9, 685-694. doi:10.1016/S1097-2765(02)00480-X 
25. Buddruhs, N.; Pradella, S.; Göker, M.; Päuker, O.; Pukall, R.; Spröer, C.; Schumann, P.; Petersen, J.; Brinkhoff, T. Int. J. Syst. Evol. Microbiol. 2013, 63, 4340-4349. doi:10.1099/ijs.0.053900-0

26. Dogs, M.; Voget, S.; Teshima, H.; Petersen, J.; Davenport, K.; Dalingault, H.; Chen, A.; Pati, A.; Ivanova, N.; Goodwin, L. A.; Chain, P.; Detter, J. C.; Standfest, S.; Rohde, M.; Gronow, S.; Kyrpides, N. C.; Woyke, T.; Simon, M.; Klenk, H.-P.; Göker, M.; Brinkhoff, T. Stand. Genomic Sci. 2013, 9, 334-350. doi:10.4056/sigs.4448212

27. Bruhn, J. B.; Nielsen, K. F.; Hjelm, M.; Hansen, M.; Bresciani, J.; Schulz, S.; Gram, L. Appl. Environ. Microbiol. 2005, 71, 7263-7270. doi:10.1128/AEM.71.11.7263-7270.2005

28. Cude, W. N.; Buchan, A. Front. Microbiol. 2013, 4, No. 336. doi:10.3389/fmicb.2013.00336

29. Biebl, H.; Allgaier, M.; Tindall, B. J.; Koblizek, M.; Lünsdorf, H.; Pukall, R.; Wagner-Döbler, I. Int. J. Syst. Evol. Microbiol. 2005, 55, 1089-1096. doi:10.1099/ijs.0.63511-0

30. Martens, T.; Heidorn, T.; Pukall, R.; Simon, M.; Tindall, B. J.; Brinkhoff, T. Int. J. Syst. Evol. Microbiol. 2006, 56, 1293-1304. doi:10.1099/ijs.0.63724-0

31. Thole, S.; Kalhoefer, D.; Voget, S.; Berger, M.; Engelhardt, T.; Liesegang, H.; Wollherr, A.; Kjelleberg, S.; Daniel, R.; Simon, M.; Thomas, T.; Brinkhoff, T. ISME J. 2012, 6, 2229-2244. doi:10.1038/ismej.2012.62

32. Thiel, V.; Kunze, B.; Verma, P.; Wagner-Döbler, I.; Schulz, S. ChemBioChem 2009, 10, 1861-1868. doi:10.1002/cbic.200900126

33. Müller, K.-D.; Husmann, H.; Nalik, H. P.; Schomburg, G. Chromatographia 1990, 30, 245-248. doi:10.1007/BF02319701

34. Scribe, P.; Guezennec, J.; Dagaut, J.; Pepe, C.; Saliot, A. Anal. Chem. 1988, 60, 928-931. doi:10.1021/ac00160a019

35. Rontani, J.-F.; Christodoulou, S.; Koblizek, M. Lipids 2005, 40, 97-108. doi:10.1007/s11745-005-1364-6

36. Kerger, B. D.; Nichols, P. D.; Antworth, C. P.; Sand, W.; Bock, E.; Cox, J. C.; Langworthy, T. A.; White, D. C. FEMS Microbiol. Ecol. 1986, 38, 67-77. doi:10.1111/j.1574-6968.1986.tb01954.x

37. Vincenti, M.; Guglielmetti, G.; Cassani, G.; Tonini, C. Anal. Chem. 1987, 59, 694-699. doi:10.1021/ac00132a003

38. Bierl-Leonhardt, B. A.; DeVilbiss, E. D. Anal. Chem. 1981, 53, 936-938. doi:10.1021/ac00229a055

39. Gaudelli, N. M.; Townsend, C. A. J. Org. Chem. 2013, 78, 6412-6426. doi:10.1021/jo4007893

40. Neises, B.; Steglich, W. Angew. Chem., Int. Ed. Engl. 1978, 17, 522-524. doi:10.1002/anie.197805221

41. Agarwal, V.; Diethelm, S.; Ray, L.; Garg, N.; Awakawa, T.; Dorrestein, P. C.; Moore, B. S. Org. Lett. 2015, 17, 4452-4455. doi:10.1021/acs.orglett.5b02113

\section{License and Terms}

This is an Open Access article under the terms of the Creative Commons Attribution License

(http://creativecommons.org/licenses/by/4.0), which permits unrestricted use, distribution, and reproduction in any medium, provided the original work is properly cited.

The license is subject to the Beilstein Journal of Organic Chemistry terms and conditions:

(https://www.beilstein-journals.org/bjoc)

The definitive version of this article is the electronic one which can be found at:

doi:10.3762/bjoc. 14.112 